\title{
An assessment of venues providing public access to ICT: a tale of 25 countries.
}

\author{
Christopher Coward \\ Center for Information \& Society, \\ University of Washington. \\ ccoward@u.washington.edu
}

\author{
Ricardo Gomez \\ Center for Information \& Society \\ University of Washington. \\ rgomez@u.washington.edu
}

\author{
Rucha Ambikar \\ Center for Information \& Society \\ University of Washington. \\ rucha@u.washington.edu
}

\begin{abstract}
This paper is based on a comparative study of venues that provide public access to information and communication technologies in 25 countries. We study how diverse people can and do access and use ICT and what factors influence availability at these venues. Our aim, through such an analysis is first to map what is available through the public access venues in these countries and second to arrive at policy recommendations to increase public access in these countries.
\end{abstract}

\section{Introduction}

Providing public access to information and communication technologies (ICT) has long been seen as an important solution to the issues of the digital divide. Early interventions aiming to lessen the gap between the digital haves and have-nots prioritized access to information through digital technologies, resulting in policy where providing computers was seen as the single most important factor to lessen the digital divide. This accessoriented approach, has however, been criticized following the failure of early interventions that focused solely on providing access to computers and the internet and associated ICT. (DiMaggio, 2004; Hargittai, 2003, Warschauer, 2003). The conceptualization of the digital divide itself has shifted in recent years, taking into cognizance other factors that influence the access and use of information and communication technologies, including different aspects of socio-economic development, environmental and political factors (Bridges.org, 2005; Wilson III, 2006). Our study was aimed at examining this range of social, economic, political, environmental factors influencing the access and use of ICT.

This study maps the landscape of public access in our sample of 25 countries with developing economies across the world. The study was conceived as a collaborative project with local research teams in each of the sample countries contributing to the process of formulating the research design, designing research questions that allowed us to explore locally relevant issues and participating in an iterative process of data collection and analysis that enriched our understanding of the field. The study focuses on venues providing public access to information and communication, particularly through the use of digital ICT. Here we use the term public access to refer to institutional locations that offer access to information, with or without the use of ICT and that are open to the public without restrictions that exclude some over others. Schools and academic institutions that restrict access to their libraries to students or their respective staff populations alone were not considered as public access venues for this study.

We prioritized a comparative study of three basic kinds of public access venues - public libraries, telecentres and cybercafés. Earlier studies have engaged in analyzing either telecentres or public libraries individually (Gomez and Reilly, 2001; Whyte and Whyte, 2000; Selwyn, 2002; Hull, 2003). Our study is unique in that it engages a comparative analysis of public libraries; and telecentres and cybercafés mapping the breadth of venues that provide public access to ICT. Through such analysis, we aim to arrive at policy recommendations to increase public access to ICT in a manner that is most beneficial to those currently underserved.

This research study is an 18-month process ending December 2008. This paper is based on preliminary results and the second phase of research is underway at the time of the writing of this paper. The analysis and recommendations we present here are preliminary but provide insight into the landscape 
of public access to ICT in these 25 countries nevertheless.

\section{Sample country and venue selection}

The sample countries for the study were chosen from countries that are economically on the lower-to middle scale globally. Countries at the poor end of the economic spectrum as well as poor and disadvantaged communities in the more affluent countries are subject of other studies that are planned or currently underway at our research center in the University of Washington (UW).

To arrive at our sample size of 25 countries, we first used the gross national per capita income, the Human Development Index as well as the population of countries (above 1 million and below 1 billion) to narrow down our choices to 70 countries. We then considered factors such as freedom of press, physical security of researchers, to arrive at 54 countries in which independent research could be conducted. The next stage of sample selection involved the creation of two indices that indicated the ICT needs and readiness of each country to select a further 30 countries.

The needs index was created using three indicators - inequality, ICT usage and ICT cost. We developed proxy indicators for each of these three factors. To gauge inequality we used income inequality $^{1}$ as a proxy to represent geographic, ethnic, gender inequalities. Inequality in these cases suggested greater potential need for public access to ICT. We used Internet users per capita ${ }^{2}$ to represent ICT usage. In this case, lower use of the Internet indicated a greater need for public access venues. ICT cost was represented by understanding the lowest broadband cost as a percentage of monthly income $^{3}$. The higher cost of broadband suggested a greater need for public access.

The readiness index rested on three factors as well - politics, skills and ICT infrastructure. We used secondary data to gather information about government policies prioritizing ICT (both present and future) to represent politics in this index. Greater government and regulatory support for ICT indicated a higher level of ICT readiness. The skills factor considered literacy (where school enrollment ${ }^{4}$ was used as a proxy indicator). Higher literacy levels

\footnotetext{
${ }^{1}$ Gini index (2006) from United Nations Development program.

${ }^{2}$ Data from CIA World Factbook (2007).

${ }^{3}$ Data from International Telecommunications Union's World Information Society Report (2006).

${ }^{4}$ International Telecommunication Union opportunity skills index (2007).
}

presumably indicate a higher readiness level for ICT usage. To measure ICT infrastructure we used the density of phones, mobiles and Internet bandwidth ${ }^{5}$ as a proxy indicator.

The final selection of 25 countries was based on four additional criteria - regional representation, number of public libraries per country, availability of qualified local research partners and tipping factors such as movements to increase public access, known plans for future infrastructure development. Local researchers were selected through an iterative process which included a call for expressions of interest which generated 220 responses from researchers around the world. We then circulated a request for qualifications resulting in over 50 proposals to conduct local research in partnership with UW. A final group of 19 local qualified research teams (with some teams conducting research in more than one country) were selected to conduct this study which was coordinated by our research team at the UW.

Based on all these criteria, we arrived at the following sample of 25 countries -

\begin{tabular}{|c|c|c|c|}
\hline \multirow{2}{*}{\multicolumn{2}{|c|}{$\begin{array}{l}\text { Needs \& } \\
\text { Readiness }\end{array}$}} & \multicolumn{2}{|c|}{ Needs } \\
\hline & & \multirow[b]{2}{*}{$\begin{array}{c}\text { Higher and } \\
\text { Medium } \\
\text { Algeria } \\
\text { Brazil } \\
\text { Colombia } \\
\text { Dominican } \\
\text { Republic } \\
\text { Georgia } \\
\text { Kazakhstan } \\
\text { Peru } \\
\text { Philippines } \\
\text { South Africa } \\
\text { Sri Lanka }\end{array}$} & \multirow{2}{*}{$\begin{array}{c}\text { Lower } \\
\text { Argentina } \\
\text { Costa Rica } \\
\text { Egypt } \\
\text { Malaysia } \\
\text { Moldova } \\
\text { Mongolia } \\
\text { Turkey }\end{array}$} \\
\hline \multirow[t]{2}{*}{ 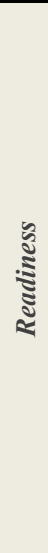 } & 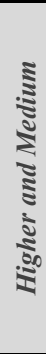 & & \\
\hline & 亏े & $\begin{array}{c}\text { Bangladesh } \\
\text { Ecuador } \\
\text { Honduras } \\
\text { Namibia } \\
\text { Nepal } \\
\text { Uganda }\end{array}$ & $\begin{array}{c}\text { Indonesia } \\
\text { Kyrgyzstan }\end{array}$ \\
\hline
\end{tabular}

Figure 1 Needs and Readiness of public access to ICT

The cumulative scores assigned to each country using the factors of inequality, ICT usage, ICT cost, politics, ICT infrastructure and skills allowed us to divide the twenty five countries into different tiers of high, medium and low. These needs and readiness indices are based on secondary data and provide an early indication of what the best opportunities for policy interventions with a view to increasing public access to ICT may be. These indices also offer a base

\footnotetext{
${ }^{5}$ International Telecommunication Union opportunity network index (2007).
} 
for comparison with the results of the comparative analysis at the end of this study.

\section{Analytic framework and methodology: the Integrated Iterative Approach (IIA)}

This research study was designed as a participatory process. We committed to approaching the process of research design and implementation in multiple steps; with input from multiple stakeholders to ensure that all key categories and dimensions of analysis were addressed and to make sure that the most meaningful questions were asked in the most meaningful way during the research. Our aim, through this process has been to arrive at findings that are useful, credible, dependable and trustworthy. (Denzin \& Lincoln, 2005; Lincoln, 1995; Villiers, 2005). We formalized our approach to research in the Integrated Iterative Approach (IIA). The IIA emphasizes a multi-disciplinary approach to any research study and presents two important guidelines to ensure that the research is meaningful and useful (1) An integrated approach where each stakeholder is represented and (2) An iterative process of research design, implementation and analysis that regularly revisits the research questions, findings and other insights to identify trends and patterns as they emerge in the research process.

The selection of our sample countries embodied the first iterative step in this research as we utilized several criteria to arrive at our sample of 25 countries. Our next step was to recruit expert local research partners in all our sample countries and to undertake a series of research planning workshops. The Real Access/ Real Impact (RA/RI) framework was chosen as a starting point for the research design during these workshops. Developed by Bridges.org in South Africa, this framework proposes a list of twelve social, economic, political, educational, cultural and environmental factors that influence public access.

While the RA/RI framework provided a large list of factors influencing access and use of ICT, we critiqued the static nature of this list. Through the IIA approach we determined that a more dynamic approach was needed to measure these factors examining historical factors as well as future implications of public access to ICT. Another important point of consideration was also the unidirectional approach to information and communication within the RA/RI framework. In our study, we wished to examine not only what was provided by different venues in terms of ICT, but also the use and appropriation of technologies by the people which reflected their particular information and communication needs. With an intention of mapping unintended uses of technology, we added the category of social appropriation of technology to our list of factors influencing public access and use of ICT. The regional and international environment as an influencing factor was added to our list based on the advice of our research partners. We divided these factors into three larger themes - Equitable Access, Human Capacity \& Relevance and Enabling Environment (or Access, Capacity and Environment in short) to arrive at this final list of factors:

Access

- Physical access to technology

- Appropriateness of technology

- Affordability of technology \& technology use

Capacity

- Human capacity and training

- Locally relevant content, applications and services

- Integration into daily routine

- Social appropriation of technology

Environment

- Socio-cultural factors

- Local and macro-economic environment

- Political will \& public support

- Legal\& regulatory framework

- Regional \& international environment

These fourteen factors formed the basis of a research design that was adapted to local contexts. Field research was divided into two phases of research, to allow for preliminary results and analysis to inform the next phase of research. Preliminary analysis of Phase I research findings was undertaken with a diverse group of researchers comprised of the lead researchers, faculty members, representatives of the donors supporting this study. While the IIA informed our research design, to allow for new themes to emerge, the preliminary analysis was conducted in a bottoms-up approach. Such an approach provided us with insight in the three larger themes of analysis set out by the IIA (Access, Capacity and Environment. At the same time, we gathered exciting new insight into the field when we received information about things we had not asked for. We invited responses to our preliminary analysis based from our research partners in 24 countries. What we present next is based on our common analysis of the data gathered in Phase I and has informed research design in Phase II which is currently underway. 


\section{Preliminary Findings: Regional Themes}

Our preliminary results reflect the diversity of venues that offer public access to information and communication technologies. We received preliminary figures that estimated the number of public libraries, telecentres and cybercafés; along with factors influencing their access and use. We present certain regional themes within the sample countries -

\subsection{Eastern Europe and Eurasia}

The countries of Eastern Europe and Eurasia in our sample (Georgia, Moldova, Kyrgyzstan, and Kazakhstan) shared a common history as part of the former Soviet Union. With particular reference to public libraries in these countries, remnants of the old Soviet administration has left a cultural legacy of trust in public libraries. The population of Georgia and Kyrgyzstan reported that while the people valued public libraries, funding streams had dried up over the last sixteen years, leaving outdated information in the libraries. At the present libraries are considered irrelevant due to this lack of current information leading to lessened value of public libraries as such. As a cyclical effect of this lessened value placed on public libraries, the prospects of future funding appear bleak.

\subsection{Latin America}

The countries from Latin America in our sample (Argentina, Brazil, Colombia, Ecuador, Honduras, and Peru) reflected many elements of a shared cultural heritage, including common languages popular in the region. Latin America is home to regional organizations that are engaged in developing public access venues. Economies of scale in the region may also make planning policy interventions easier, although current lack of infrastructure and political instability could pose roadblocks in such policy interventions.

One of the most resounding findings in this region has been the enormous popularity of cybercafés. Honduras and Peru reported that more than half of all ICT usage in these countries takes place at cybercafés. The enormous and steadily increasing popularity of mobile phones is also being seen as rendering public access to information easier. In general, public libraries did not enjoy much popular patronage but were seen as places for academicians.

\subsection{South Asia}

Bangladesh, Nepal and Sri Lanka were the three countries from South Asia that were included in our sample. As expected, a common observation among these three countries was that a larger proportion of the countries' resources were earmarked for fulfilling the basic needs of their populations. Common challenges in the three countries included lack or shortage of infrastructure including electricity, roads, availability of network cables providing internet access, etc. The geography of all three countries posed significant barriers to an easy increase in public access to ICT; be it the mountainous terrain of Nepal, the tsunami affected regions of Sri Lanka or the seasonal flooding in Bangladesh. On the positive sides, governments of all three countries are reported to be in favor of proliferating ICT with measures such as encouraging foreign investment in this area starting to provide inroads in this area.

\section{Understanding Access, Capacity and Environment}

We based the research design for this study on the categories of Access, Capacity and Environment. While each country research team adapted these categories of questions to fit their local context, our preliminary findings have validated the value of such an organizational scheme. We present the preliminary findings in each category here and expect Phase II to fully develop these research themes.

\subsection{Equitable Access}

The category of access studied physical access to technology, appropriateness of technology and affordability of technology \& technology use. Let us consider each of these factors in order -

As expected, the geography of a nation influenced physical access to ICT. One of the most common reports we received was the concentration of venues providing public access to ICT around the capital city of the country. For example, while access to ICT is widely accessible in Kathmandu, Tbilisi, and Cairo, it is much less accessible in the rural areas outside the capitals of Nepal, Georgia, and Egypt. This theme of uneven distribution of venues was echoed in the urban vs. rural areas. In many countries a lack of general infrastructural support has prevented proliferation of ICT, in some unique cases such as in Namibia, communities have harnessed solar power and use diesel generators to power wireless 
connectivity in schools.

The appropriateness of technology was reported to be a common concern by our research partners. In countries such as Ecuador, Georgia, Peru, South Africa and Sri Lanka, we received strong indications that lack of content in local languages, as well as lack of locally relevant content prohibits users from accruing the benefits provided by public access to ICT.

The cost of various venue types was cited by numerous researchers as prohibitive for the many populations in obtaining access to information. In addition to the fee-for-service costs, a common thread across countries such as Peru, Egypt and Algeria was the inclusion of costs other than ICT usage costs - the high cost of transportation to get to the venues, and the likelihood of poorer communities to be working during the regular hours of operation, as was reported in the case of public libraries in Egypt. On a positive note, countries such as Bangladesh, Mongolia, Kyrgyzstan, Kazakhstan and Moldova reported expectations of lower costs of ICT usage in the near future.

\subsection{Human Capacity and Relevance}

The category of capacity examined human capacity \& training, locally relevant content, applications and services, the integration into daily routines, trust in technology and social appropriation of the technology.

More than half of the countries included in our sample reported a lack of trained knowledge workers who would help the public access and use ICT. Kazakhstan, for example reported that even with a high literacy rate in the country (99.5\%) technical literacy lagged far behind due to lack of trained teachers in the area. Countries such as Moldova also reported the phenomenon of brain drain where qualified staff was leaving rural areas for urban centres, leaving rural patrons without recourse to help in ICT usage.

Lack of locally relevant content was nearunanimously reported to be a barrier to ICT access and use. In countries such as Brazil, Costa Rica, Georgia, Sri Lanka and South Africa, our researchers reported a shortage of content in local languages, as well as limited access to current information. Brazil in particular, noted that the obscurity of official information provided renders access to current local information more important.

Integration into daily routines is critically tied to accessibility. Transportation issues have caused difficulty in accessing venues providing ICT in Peru. Honduras researchers reported that the inability to communicate with loved ones who had emigrated overseas produced significant information gaps.

Trust in technology is necessary if increasing public access to ICT is to benefit those currently underserved. Ecuador reported that with government restrictions limiting people's access and use of technology, ICT was not seen as a valuable resource. A strong theme that emerged through our findings was people's inability to see the benefits of information and ICT in their daily lives. In countries such as Costa Rica, Egypt, Moldova, Nepal and Sri Lanka, there was a reported low awareness of the benefits of technology and a lack of recognition of any information gap.

Social appropriation of technology was added to our matrix of factors affecting use and access of ICT following the need to understand unintended use of technologies that are provided at public access venues. In countries such as Sri Lanka, we found a strong criticism of content provided that was seen as presenting information as well as technology through a Western bias. Researchers there have reported people's wishes to engage in content production that presents information with a differing view-point. In countries in Latin America, we also received reports of community organizations being formed in public access venues that champion local issues, not directly related to ICT. The public access and use of ICT in such instances has promoted civic engagement. These themes of social appropriation are being further investigated in Phase II of research.

\subsection{Enabling Environment}

The category of environment addressed factors such as socio-cultural factors, local and macroeconomic environment, political will and support, legal and regulatory framework, as well as the regional and international environment.

As can be expected traditional socio-cultural inequalities such as class, gender, minority status, etc severely affected access and use of ICT, along with location in urban or rural areas. In general, gender was reported to be a barrier to accessing venues providing ICT in countries such as Algeria, Egypt, Turkey, and Nepal, where socio-cultural factors disadvantaged women in the social sphere. However, an exception regarding public libraries was reported in Egypt, where libraries were considered safe public places for women to occupy.

The historical culture of information was reported by several researchers as playing an important role in access to information. The governments of Turkey and Egypt, it was reported, did not freely provide information to the public. This 
trend has continued to the present day, where government agencies have been slow to provide information that is easily accessible and relevant to people's lives.

Local and macro economic factors heavily influenced public access to information and communication through ICT. Factors such as poverty, conflict, migration, and unemployment, necessarily divert government resources to the fulfillment of basic needs, which was reported to result in a lower prioritization of public access to ICT. This was particularly true in the case of countries such as Honduras and Nepal. Public access to information and ICT thus suffered as a result of the competition for scarce government resources.

In general, we observed increasing political will and political support for public access to ICT. This, however, was not always formalized in the legal and regulatory framework, creating a mismatch between aspiration and reality in the country. Researchers reported a lack of follow through on planned government initiatives due to changes in government in some Latin American countries. In several cases, changes in government were attributed to conflict or war. In Philippines we received reports that while public access and use of ICT is growing rapidly, especially through the use of mobile phones the severe lack of political support in the country has created significant barriers.

In the cases of Bangladesh and Sri Lanka, the government created roadblocks in the implementation of policy due to its legal and regulatory framework. For example, wi-fi services require licensing under Sri Lanka laws, creating what was reported as unnecessary delays; while network cables in Bangladesh were owned by a government telecommunication monopoly, making it near impossible to argue for lower ICT costs.

In Latin America we have received reports of initiatives that have emerged out of regional and international environment that supports the increase of public access to ICT. Investment by foreign donor agencies in the region in the field of ICT is also being cited as a common element. This is currently being investigated in greater detail.

\subsection{Comparative rankings: Access, Capacity and Environment (ACE rankings)}

In our process of analyzing the preliminary findings, we assigned a score of high, medium or low to each category of access, capacity and environment reported for each country; and finally assigned a single score that represented the combination of these three factors. These groupings of lower barriers, medium barriers and stronger barriers are relative to other countries in the sample and not absolute scores. One of the surprising insights through such grouping is the similarities in barriers and opportunities across countries, regardless of geographic location.

These low, medium and high represent a new understanding of the opportunities to foster more widespread and meaningful public access to ICT in these countries. We expect to further enrich our understanding of this typology of public access based on the findings of the next phase of research.

We present this comparative chart below. (N.B. Dominican Republic, Malaysia and Indonesia are not represented below due to the incomplete nature of information we have received so far.)

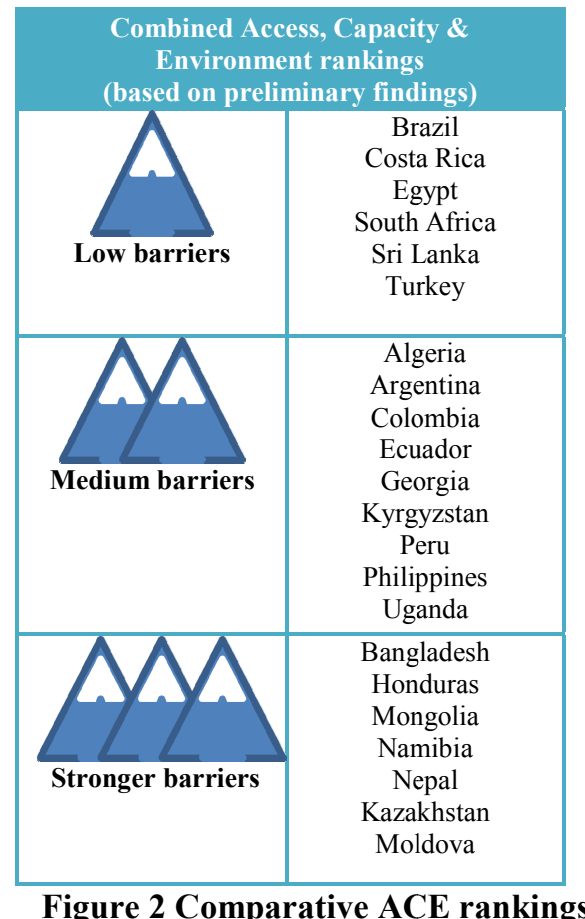

The creation of this combined matrix of access, capacity and environment has provided us with further insight into the realities of public access to ICT in our sample countries. While we have noted that in roughly two-third of the cases, the needreadiness indices were borne out through our preliminary findings, there were some surprising elements to our findings. Philippines, as we noted in the needs-readiness indices was significantly high in terms of the possible success of ICT interventions. The low score that it received in environment category, however, moved it to the medium range in the ACE rankings. The needs-readiness indices 
ranked Egypt in a lower section than the ACE rankings, an effect of the championship of the First Lady of Egypt, who is dedicated to increasing public access to ICT. Colombia and Peru which ranked high in the needs-readiness indices were scored lower on the ACE rankings due to conspicuously uneven distribution of resources and infrastructure in urban and rural areas.

\section{Emerging Insights}

Our preliminary findings have provided us with some interesting new insights, grouped around the following four themes.

\subsection{Collaboration Opportunities: Venues}

Our research points to the need for better and effective collaboration among existing venues as the most promising opportunity for future intervention. One of the strongest themes that emerged was the recommendation of better collaboration between venues already providing access to ICT - whether they are between public libraries and community libraries (as was the case in Argentina and Nepal) or between various government initiatives providing similar services, such as in Sri Lanka. Most country research teams also recommended collaboration between different types of libraries and telecentres and cybercafés as the policy that would have most impact, particularly in the case of South Africa and Peru.

\subsection{Shifting Media Landscape: Outside of Venues}

Beyond focusing on venues, preliminary findings shed light on a variety of new experiences and tools that are being explored and used in different contexts to meet information needs of marginalized communities. Some key opportunities in this field point to community radio in Nepal and Uganda, the use of instant messaging in Philippines, the use of Wi-Fi hotspots in Peru. Brazil, Colombia, Honduras, Peru, Philippines, Turkey among others reported the growing use of mobile phones that replaced the access of ICT in any particular venue.

\subsection{Cool Factor: Where People Go}

Preliminary findings highlight the importance of working to strengthen the venues where people go, which are not necessarily the ones we had initially thought. In understanding where people go or don't go, perceptions may matter more than institutional support, training or services offered. Especially among youth, strengthening places that are perceived as "cool" and where youth like to "hang out" may be more effective ways to reaching marginalized communities. Public libraries were seen as cool or relevant in very few places. Egypt reported that public libraries were safe places, but seen primarily as places for children or women - a sentiment that was echoed in various degrees across the board. Sri Lanka and Georgia reported a trust in libraries but also that libraries were irrelevant since they provided outdated information.

\subsection{Legitimate Use: Trivial and Non-Trivial Information}

The fourth insight from preliminary findings is related to information needs and services offered. A discussion on what constitutes 'trivial' and 'non trivial information'; and what is 'acceptable' use of public access venues is an important one to engage in. For example, in one country we received information stating that cybercafés were one of the most popular venues for public access to information, but that they provided access only to trivial information. Another country team reported that youth wasted computer time by using chat while others who 'really' needed to use computers waited. Further research will concentrate on factors that influence this classification of particular uses as legitimate or not.

\section{Conclusion}

Our research study aims to map the landscape of public access to Information and communication technologies and to arrive at policy recommendations for interventions to increase such public access. Preliminary findings from our sample of 25 countries have allowed us to identify the range of venues providing public access to ICT, and allow for factors influencing their access and use to emerge. So far, we have identified areas that need further investigation, both in terms of verifying actual numbers of venues and services provided at public access venues. Interestingly, we have also received indications of the comparative use and value of public libraries, telecentres and cybercafés in comparison to each other. Phase II of research will further nuance this understanding. The emerging insights point to areas of policy recommendations and it is our hope to consolidate the current state of knowledge in the field 
of public access to ICT in order to recommend practical and scalable interventions to increase access and use of ICT particularly for those currently underserved at the end of this process.

\section{References}

[1] Alkalimat, A. and Williams, K. (2001) Social capital and cyberpower in the African American community: a case study of a community technology center in the dual city. In L. Keeble and B. Loader (eds) Community Informatics: Shaping Computer-mediated Social Relations, London: Routledge, pp. 177-203.

[2] Barzilai-Nahon, K. (2006). Gaps and Bits: Conceptualizing Measurements for Digital Divide/s. The Information Society: an international journal, 22(5).

[3] Bridges.org. (2005). Real Access, Real Impact Criteria [Electronic Version], from http://www.bridges.org/Real Access Accessed June 2008.

[4] Castells, M. (1996) The Information Age: Economy, Society and Culture. Vol. I: The Rise of the Network Society, Oxford: Blackwell.

[5] Denzin, N., \& Lincoln, Y. (2005). The SAGE Handbook of Qualitative Research (3rd ed.): Sage.

[6] DiMaggio, P. and Hargittai, E. (2001). From the Digital Divide to digital inequality: Studying Internet use as penetration increases. Princeton, NJ: Center for Arts and Cultural Policy Studies, University Working Paper 15.

[7] DiMaggio, P., Hargittai, E., Celeste, C., and Shafer, S. (2004). Digital inequality: From unequal access to differentiated use. In Social inequality, ed. K Neckerman, pp. 355-400. New York: Russell Sage Foundation.

[8] Gómez, R., \& Reilly, K. (2002). Comparing approaches: Telecentre evaluation experiences in Asia and Latin America. The International Information \& Library Review 34(1), 22.

[9] Gómez, R., \& Casadiego, B. (2002). Letter to Aunt Ofelia: Seven Proposals for Human Development Using New Information and Communication Technologies. Ottawa, Lima, Bogota: IDRC (PAN Americas), ITDG, Raíces Mágicas.

[10] Gómez, R., \& Martínez, J. (2001). The Internet... Why? and what for? Ottawa, San José: IDRC, Acceso.

[11] Gómez, R., \& Ospina, A. (2001). The Lamp Without a Genie: using the Internet for development without expecting miracles. Journal of Development Communication, 12(2).

[12] Gurstein, M. (2003). Effective use: A community informatics strategy beyond the Digital Divide. First Monday, 8(12).

[13] Heeks, R. (2007). Impact Assessment of ICT4D Projects: A Partial Review of Frameworks. Unpublished manuscript.
[14] Lincoln, Y. S. (1995). Emerging Criteria for Quality in Qualitative and Interpretive Research. Qualitative Inquiry, 1(3), 275-289.

[15] Mark, J., Cornebise, J. and Wahl, E. (1997) Community Technology Centres: Impact on Individual Participants and Their Communities, Newtown, MA: Education Development Centre.

[16] Peters, Teresa. Bridging the Digital Divide. The Evolving Internet. Volume 8, No. 3. November 2003.

[17] Reich, R. (1991) The Work of Nations: A Blueprint for the Future, London: Simon \& Schuster.

[18] Selwyn, Neil (2003) ICT for all? Access and use of Public ICT Sites in the UK, Information, Communication \& Society, 6:3, 350 - 375 .

[19] UNCTAD. (2007). Promoting livelihood through telecentres In INFORMATION ECONOMY REPORT 2007-2008. Science and technology for development: the new paradigm of ICT (pp. 269320).

[20] United Nations. (2007). Promoting livelihoods through telecentres. In UNCTAD secretariat (Ed.), Information economy report 2007-2008. Science and technology for development: the new paradigm of ICT. New York and Geneva: United Nations.

[21] Villiers, M. R. d. (2005). Three approaches as pillars for interpretive information systems research: development research, action research and grounded theory. Paper presented at the 2005 annual research conference of the South African institute of computer scientists and information technologists on IT research in developing countries. Available at http://portal.acm.org/citation.cfm?id=1145675.11 45691 Accessed on June 2008.

[22]Warschauer,M.(2002).ReconceptualizingtheDigitalDivi de.FirstMonday 7(7). http://www.firstmonday.dk/issues/issue7 7/warschauer (accessed 20 May 2008).

[23] Warschauer, M. (2003). Technology and social inclusion: Rethinking the digital divide. Cambridge, MA: MIT Press.

[24] Williams, A. and Alkalimat, A. (2004) A census of public computing in Toledo, Ohio, in D. Schuler and P. Day (eds) Shaping the Network Society: The New Role of Civic Society in Cyberspace, Cambridge, MA: MIT Press.

[25] Wills, M. (1999) Bridging the digital divide, Adults Learning, 11(4): 10-11.

[26] Wilson, E. J. III. (2006). Why we need a negotiation model to explain Internet diffusion. Access to Knowledge Conference, Yale University, New Heaven, CT.

[27] Wilson, M. (2003). Understanding the International ICT and development discourse: Assumptions and implications, The Southern African Journal of Information and Communication, No. 3 , available at: http://link.wits.ac.za/journal/j0301merridy-fin.pdf Accessed on May 7, 2008. 
[28] Whyte, A. (1999). Understanding the Role of Community Telecentres in Development: A Proposed Approach to Evaluation. In Telecentre Evaluation: A Global Perspective. Paper presented at the International Meeting on Telecentre Evaluation.

[29] Whyte, A. (2000). Assessing Community Telecentres: Guidelines for Researchers. Ottawa: International Development Research Centre. 